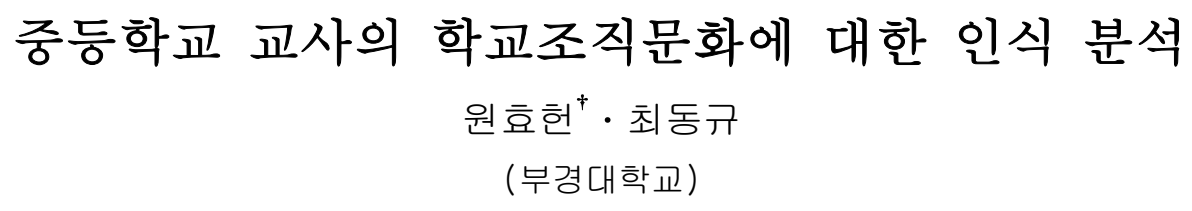

\title{
An Analysis of Teacher's Perceptions on School Organizational Culture in Secondary School
}

\author{
Hyo-Heon $\mathrm{WON}^{\dagger} \cdot$ Dong-Kyu CHOI \\ (Pukyong National University)
}

\begin{abstract}
The principal purpose of this study is to analyze school organizational culture in secondary school in Busan. This study measures background variables such as gender, teaching experience, classification of school, grade of school, and scale of school.

The results of the study are as follows : First, to see the difference on the perception of organizational culture depending on gender, female teachers have a stronger sense of professionalism, community spirit and consideration than male teachers. Second, to see the difference on the perception of organizational culture in terms of teaching experience, teachers who have more than 21 years of teaching experience have a more positive perception on decision-making and consideration than those who have 11 20 years of teaching experience. Third, to see the difference on the perception of organizational culture according to classification of school, public schools have a more positive perception on every item such as professionalism, decision-making, community spirit, and consideration than private school. Fourth, to see the difference on the perception of organizational culture in terms of classification of schools, secondary schools have a more positive perception on professionalism and community spirit than high schools. Lastly, as it is seen in the difference on the perception of organizational culture depending on scale of school, schools which have 13 35 classes have a more positive perception on professionalism than others.
\end{abstract}

Key words : Organizational culture, Secondary school teacher, School Organizational Culture

\section{I. 서 론}

어느 사회를 막론하고 교육의 성패를 좌우해온 요인에는 여러 가지가 있겠지만 이를 실질적으로 좌우해온 가장 큰 요인은 교사라 할 수 있다. 교 육의 질적 개선을 위한 모든 노력에서 그 핵심적 역할은 교사가 담당하며, 아무리 이상적인 교육
개혁이라 하더라도 교사가 앞장서지 않는 한 결 코 성공을 기대할 수는 없는 것이다. 교육의 질 은 교사의 질에 비례하거나 교사의 질을 능가할 수는 없다는 말은 교사 자질의 중요성을 단적으 로 말해주고 있다. 교육의 주체로서의 교사는 가 시적인 교육활동뿐만 아니라 잠재적 교육과정에 이르기까지 학생의 지적, 정서적, 도덕적, 사회적

† Corresponding author : 051-629-5972, wonhyo@pknu.ac.kr 
성숙에 깊은 영향을 주는 중요한 위치에 놓여 있 다. 특히 오늘날과 같은 학교교육의 위기 속에서 우리 사회가 요구하는 수많은 필요에 대응하기 위해서 교사의 역할과 책임의 중요성은 더욱 크 다고 할 수 있다. 이러한 교사의 역할과 책임의 수행은 그의 능력이나 개성, 전문적 소양 등에 의해서 결정되는 것이 사실이나 다른 한편으로는 교사가 있는 학교조직의 문화에 의해서도 달라질 수 있다.

모든 사회는 그 사회 안에 다양한 하위문화가 존재한다. 또한 모든 조직은 독특한 문화를 가진 다. 그 문화는 조직의 기능과 효과성에 영향을 미치는 것은 물론 조직 구성원들의 사고, 정서, 그리고 행동에도 영향을 미친다. 조직문화는 조 직과 사람들이 자신들의 행동에 부여하는 의미 있는 집단행동이다. 조직 가치, 비전, 규범, 언어, 시스템, 기호, 믿음과 습관을 포함한다. 심지어는 생각하고 느끼며 행동하는 것들의 패턴이며 또한 집단행동과 지각의 방법으로 새로운 조직 구성원 들에게 가르친다. 조직 문화는 사람과 사람들의 상호 작용이며, 서로 이해하는 관계와 방식에 영 향을 미친다(Schein, 1992).

학교조직도 학교조직 특유의 문화를 가진다. 학교조직문화란 학교라는 조직의 구성원들에 의 해 의혹 없이 당연한 것으로 받아들여지며, 학교 의 고유한 특성을 나타내는 공유가정, 즉 가치, 신념, 이념 목표가 조직 구성원들에게 작용되어 표출되는 상징적 행위의 복합체이다(황기수, 1998). 따라서 교사 자신들이 학교조직문화에 대 한 어떠한 신념과 가치관을 가지고 있느냐에 따 라 직무에 대한 애착, 관심, 열의와 직무만족의 정도가 다를 것이며, 교사가 문제 해결과 교육현 장의 제반 환경에 얼마나 만족하고 자신의 자질 향상을 위하여 노력하느냐에 따라서 교육의 질이 달라질 것이다.

급변하는 사회 속에서 교사들의 교직사회화 과 정 및 교직의식, 학교조직문화에 대한 인식에도 많은 변화가 있어 왔다(원효헌·남인애, 2003, 원
효헌·조명임, 2008). 지식위주의 학원 교육, 대중 매체를 통하여 폭주하는 정보의 홍수로 말미암아 교직은 지식 제공의 원천으로서의 역할도 감소되 었을 뿐만 아니라 최근 교사와 관련된 각종 사회 문제로 인해 교사의 위신은 우려할 정도로 떨어 진 상태이다. 또한 '학습자 중심의 교육' '정보화' '세계화' 등과 같이 시대적 요구를 담은 용어가 등장하면서 학교 구성원으로서의 교사의 역할은 더욱 중요해졌으나, 교사들로 하여금 계속적인 적응과 자기 개발을 요구하는 이러한 용어들은 교사들에게 심리적인 부담으로 작용하고 있는 실 정이다. 특히 2008년 근무평정부터 시행된 '교장. 교감의 다면평가', 2010년부터 전국의 모든 학교 에 전면적으로 시행되고 있는 '교원능력개발평 가', 또한 2012년의 '학생인권조례' 공포 등 최근 에 시행되고 있는 일련의 학교교육관련 여러 가 지 제도들로 인해 급변하는 교육현장의 상황에서 교육을 담당하는 주체인 교사들의 학교조직문화 에 대한 인식도 많은 변화가 있었을 것이다.

이러한 시점에서 본 연구는 학교라는 교육활동 의 조직체내에서도 가장 중추적인 위치에서 자신 에게 주어진 직무를 수행하고 있는 교사들의 학 교조직문화에 대한 인식이 어떠한가를 파악하고, 교사의 배경변인에 따른 집단간 학교조직문화에 대한 인식의 차이를 분석해봄으로써 학교조직의 효율적인 운영 및 학교조직문화의 개선 방향에 도움을 줄 수 있는 기초 정보를 제공하기 위해 수행되었으며, 이와 같은 연구 목적을 달성하기 위해 다음과 같은 연구문제를 설정하였다.

첫째, 교사의 개인 배경변인(성별, 교직경력별) 에 따라 학교조직문화에 대한 인식은 어떠한가?

둘째, 교사의 학교 배경변인(학교구분, 학교급, 학교규모)에 따라 학교조직문화에 대한 인식은 어떠한가?

\section{II. 이론적 배경}




\section{1. 학교조직문화의 특성}

학교조직은 관료적 성격과 전문적 성격을 모두 가지고 있는 이중적 구조이다. 학교는 분업화된 관료적 성격을 갖고 있지만 그 일을 수행하기 위 해 전문성이 필요하다. 바로 교장이 그런 예이다. 교장의 권위는 이 두 가지 측면이 혼합되어 있으 므로 어느 정도 혼란이 발생하고 있다(Hoy \& Miskel, 2005). 학교의 조직 목적을 달성하기 위 해 교육계획을 세우고, 이를 분담하여 학교행정 을 추진하는 측면에서 관료적인 성격을 갖지만, 실제 그러한 일을 수행하기 위해서는 고도의 전 문성이 필요하기 때문이다. 조직 내에서 교사들 로 갈수록 전문화되지만 위로 올라 갈수록 지위 계층에 따라 관료화가 요구되기 때문에 학교가 두 가지 성격을 모두 가지고 있다는 사실을 이해 해야만 구성원들의 행동 특성을 이해할 수 있다.

학교조직문화는 학교조직의 기능과 효과성에 영향을 미친다. 그리고 구성원인 교사의 특성변 인에 영향을 줄 뿐만 아니라, 학생의 특성변인에 도 영향을 미친다. 조직문화에 대한 개념은 다양 하게 정의되고 있으나, 학교조직문화에 대한 개 념정의는 별로 없다. 그래서 학교조직문화는 일 반 조직문화의 개념에 의존하게 된다(조남근, 1996). Schein(1992)은 조직문화의 주요 범주를 토 대로 학교조직문화를 구성원들이 공유하는 철학, 가치, 이념, 가정, 신념, 기대, 태도, 규범 등이 학 교라는 조직체에 한정되어 나타나는 문화라고 하 였으며, Hoy와 Miskel(2005)은 학교조직문화를 학교에서 당연한 것으로 받아들여지고 그렇게 행 동하기를 기대하는 가정, 규범, 기준, 태도, 철학, 이념 등의 결합체로 보고 있다. 김준기(1991)는 학교조직문화를 학교라는 조직체의 성원들에 의 해 의심없이 당연한 것으로 받아들여지며, 학교 의 고유한 특성을 나타내는 공유 가정인 가치, 신념, 이념, 목표가 학교조직 구성원들에게 작용 되어 표출되는 상징적 행위의 복합체라고 정의하 였다. 따라서 학교조직문화는 가치, 신념, 규범
등 학교조직 구성원들이 직무를 수행하는 방식이 라고도 할 수 있고 학교 내에서 집단 경험을 공 유하는 구성원들에게 나타나는 사고방식 및 행동 방식에 영향을 미치는 요인이라고도 할 수 있다. 이러한 학교조직문화는 학교의 공식.비공식 조직 구성원들의 개성과 학교장의 지도성 유형, 교사 들과 관리자, 교직원 상호간의 관계 등과 같은 조직체의 내적 특성들의 작용에 의하여 결정된 다. 이렇게 결정되는 각 학교의 조직문화는 그 학교의 구성원들에게 체득되고 경험되며, 그들에 게 영향을 미치는 심리적 학교조직의 환경의 총 체라고 할 수 있다.

김경미(2004)는 중등학교 조직의 교직문화를 존재가치에 대한 강한 인정성, 공적 활동 중심의 개인주의, 동학년 및 동교과 중심의 우리주의, 저 항 속에 잠재된 순응, 신뢰없는 형식적 만남 등 으로 재정리하고 있고, 박영숙·전제상(2003)은 초.중등학교 조직별 교직문화의 특성을 연구하였 는데 그 내용을 정리하면 <표 1>과 같다.

\section{2. 학교조직문화의 구성요소}

학교 조직문화는 문화의 개념을 사회체계를 구 성하는 조직체 수준에서 적용한 개념이다. 이런 학교 조직문화의 구성요소는 조직 구성원들의 행 동과 학교의 고유한 특성을 나타내는 중요한 개 념으로 가치와 신념, 이념, 목표, 규범과 관습 등 에 따라 여러 가지 요소로 구성되어 구체적인 구 성요소에 대한 견해는 학자마다 다르다.

우선 학교의 조직문화를 알아보기 위해 Patterson과 Purkey, Parker가 개발한 학교 문화 목록(School Culture Inventory : SCI)을 적용하 여 학교조직문화 요소를 살펴보면, 이는 학교에 서 행동의 범위를 작업 범위로 보고 교직원을 이 해하는 것으로서 10 개의 부문에서 각각 하위변인 을 기초로 하였다.

학교 조직문화 요소는 (1) 학교 교육 목표 (2) 권한위임 (3) 의사결정 (4) 지역사회의 인지 (5) 신 
〈표 1〉 초· 중등학교 조직문화의 특성 비교

\begin{tabular}{|c|c|c|c|}
\hline \multirow{2}{*}{ 구분 } & \multirow{2}{*}{ 초등학교 } & \multicolumn{2}{|c|}{ 중등학교 } \\
\hline & & 중학교 & 고등학교 \\
\hline $\begin{array}{l}\text { 학 교 조 직 } \\
\text { 및 문화의 } \\
\text { 일반적 특 } \\
\text { 성 }\end{array}$ & $\begin{array}{l}\text { ·국민공통교육과정 } 1 \text { 6학년 } \\
\text {.학교-학급의 모든 업무를 } \\
\text { 혼자 담당 처리 } \\
\text { ·농촌지역의 열악한 환경 }\end{array}$ & $\begin{array}{l}\text { ·국민공통교육과정 } 7 \text { 9학 } \\
\text { 년 } \\
\text { ·우선 발령, 업무 적합성 } \\
\text { 중심 보직 } \\
\text { ·전문성 지각 } \\
\text {.행정우선 업무분장 } \\
\text {.다양한 조직 소속 약한 } \\
\text { 조집 응집력 } \\
\text {.여성비율이 증가 }\end{array}$ & $\begin{array}{l}\text { ·국민공통교육과정 } 10 \text { 학년 } \\
\text { 심화선택과정 } \\
\text { ·교육행정 운영과 교육과정 } \\
\text { 운영의 혼재 } \\
\text { ·진학지도 우선 인식 } \\
\text { ·학습지도방법, 교육정보화 } \\
\text { 등에 무관심 } \\
\text { ·집단 이기주의와 편의주의 } \\
\text { ·공식-비공식 문화의 혼재 }\end{array}$ \\
\hline $\begin{array}{l}\text { 교 원 정 책 } \\
\text { 변화에 대 } \\
\text { 한 구성원 } \\
\text { 의식 및 } \\
\text { 대응양상 }\end{array}$ & $\begin{array}{l}\text { ·교원수급 정책차질로 인한 } \\
\text { 교원의 질적 저하, 사기저 } \\
\text { 하, 교권추락, 학교 붕괴감 } \\
\text { 형성 } \\
\text { 충원 절실, 긍지 상실, 교 } \\
\text { 사 집단간 갈등 심화, 패배 } \\
\text { 감 등 }\end{array}$ & $\begin{array}{l}\text { ·중복적인 교육청 소속 } \\
\text { 교육행정 } \\
\text { ·수동적인 교육정책 입장 } \\
\text { ·긇임없는 정체성 시비 } \\
\text { ·획일적, 굴종적인 교무실 } \\
\text { 문화 }\end{array}$ & $\begin{array}{l}\text { ·교원정책 변화에 대한 비 } \\
\text { 참여적, 부정적 인식 } \\
\text { ·정년 단축 등 사기저하 } \\
\text { 입시 비선택 과목 교사의 } \\
\text { 불안감 } \\
\text { ·공동체 의식의 약화 또는 } \\
\text { 해체 }\end{array}$ \\
\hline $\begin{array}{l}\text { 교 직 문 화 } \\
\text { 의 변화 } \\
\text { 저해 요인 }\end{array}$ & $\begin{array}{l}\text { ·지시와 낮은 지원 } \\
\text { ·심리적 압박과 스트레스 } \\
\text { ·무관심과 비협조 } \\
\text { ·승진과 전보를 위한 순응 } \\
\text { 적 문화 } \\
\text {.행정업무 처리 우선 } \\
\text {.학교청소 교사부담 } \\
\text { ·열악한 복지시설 } \\
\text { ·소극적 분위기 } \\
\text { ·형식적 장학지도 } \\
\text { ·소극적 학생지도 } \\
\text { ·부족한 정보공유 } \\
\text { ·전문성 확보부족 }\end{array}$ & $\begin{array}{l}\text { ·교사들의 일방 통행식 } \\
\text { 문화 } \\
\text { ·수평적 교사 상호간 문 } \\
\text { 화교류의 단절 } \\
\text { ·공문과 결재를 통한 감 } \\
\text { 독 강화 } \\
\text { ·경직된 침묵문화 } \\
\text { ·상명 하달식 행정구조 } \\
\text { ·교사의 협소한 영역에서 } \\
\text { 의 참여 권한 }\end{array}$ & $\begin{array}{l}\text { ·교수학습의 과중한 업무와 } \\
\text { 시간부족 } \\
\text { ·교직 신념의 차이로 인한 } \\
\text { 의견대립 } \\
\text { ·학교운영에 대한 무관심, } \\
\text { 애착심 결여, 참의 의욕 부 } \\
\text { 족, 인사 안함 } \\
\text { ·관료적 학교경영 } \\
\text { ·대화, 토론문화 부족 } \\
\text { ·개인주의, 교원집단간 갈등 } \\
\text { ·전문성 부족, 노력부족 }\end{array}$ \\
\hline $\begin{array}{l}\text { 교직문화의 } \\
\text { 변화 촉진 } \\
\text { 요인 }\end{array}$ & $\begin{array}{l}\text { ·학교와 학생을 위한 마음 } \\
\text { ·겸손과 예의 } \\
\text { ·상호 존경과 협력 }\end{array}$ & $\begin{array}{l}\text { ·교직원 한마음 연수 } \\
\text { ·보직교사의 연수 }\end{array}$ & $\begin{array}{l}\text { ·교과목과 수업운영의 자율 } \\
\text { 성 보장과 협의 } \\
\text { ·일과 운영의 융통성 }\end{array}$ \\
\hline $\begin{array}{l}\text { 조 직 구 성 } \\
\text { 공통적 특 } \\
\text { 징 }\end{array}$ & $\begin{array}{l}\cdot \text { 교장-교감-교사 상호 관계 } \\
\text { ·교육청-교장, 교감-부장, 부 }\end{array}$ & $\begin{array}{l}\text { 엉원 조직) } \\
\text { 행정직원 관계(업무항 }\end{array}$ & (계선조직) \\
\hline
\end{tabular}

※출처: 박영숙 - 전제상(2003)에서 재정리 후 작성

뢰 (6) 자질 (7) 인식 (8) 배려 (9) 성실 (10) 다양성 의 측정요소로 구성되었으며 각 측정 내용을 관 계 깊은 것끼리 관련을 맺어서 (1) 조직구조 (2) 의사결정 (3) 공동체 의식 (4) 신뢰 (5) 배려 (6) 성 실 (7) 다양성으로 분류하였으며 각각의 의미는
다음과 같다(전영배, 1993 재인용).

(1) 조직구조 : 조직의 목표를 설정하고 이를 달성하기 위하여 조직 구성원의 행동을 통제하고 방향을 제시하는데 활용하는 규정을 말한다.

(2) 의사결정 : 조직의 문제해결 과정에서 구성 
원에게 주어지는 책임과 기회의 정도를 말한다.

(3) 공동체 의식 : 조직 구성원이 갖고 있는 조 직에 대한 일체감을 말한다.

(4) 신뢰성 : 조직목표에 대해 긍정적으로 생각 하고 조직구성원이 서로 신뢰하고 능동적으로 행 동하는 것을 말한다.

(5) 배려성 : 조직 구성원의 능력 발휘 결과에 따른 적절한 보상을 말한다.

(6) 성실성 : 조직 구성원이 성실하고 정직하게
생활하는 태도를 말한다.

(7) 다양성 : 조직목표 달성과 가치를 추구하는 데 있어서 사용하는 다양한 방법을 말한다.

본 연구에서 학교 조직문화의 구성요소를 선정 하기 위해 먼저 선행연구를 분석하여 요소들을 추출할 필요가 있었다. 학교 조직문화에 대한 연 구자들에 의해 선정된 구성요소들을 정리해 보면 <표 2>와 같다.

〈표 2〉 학교조직문화의 구성요소

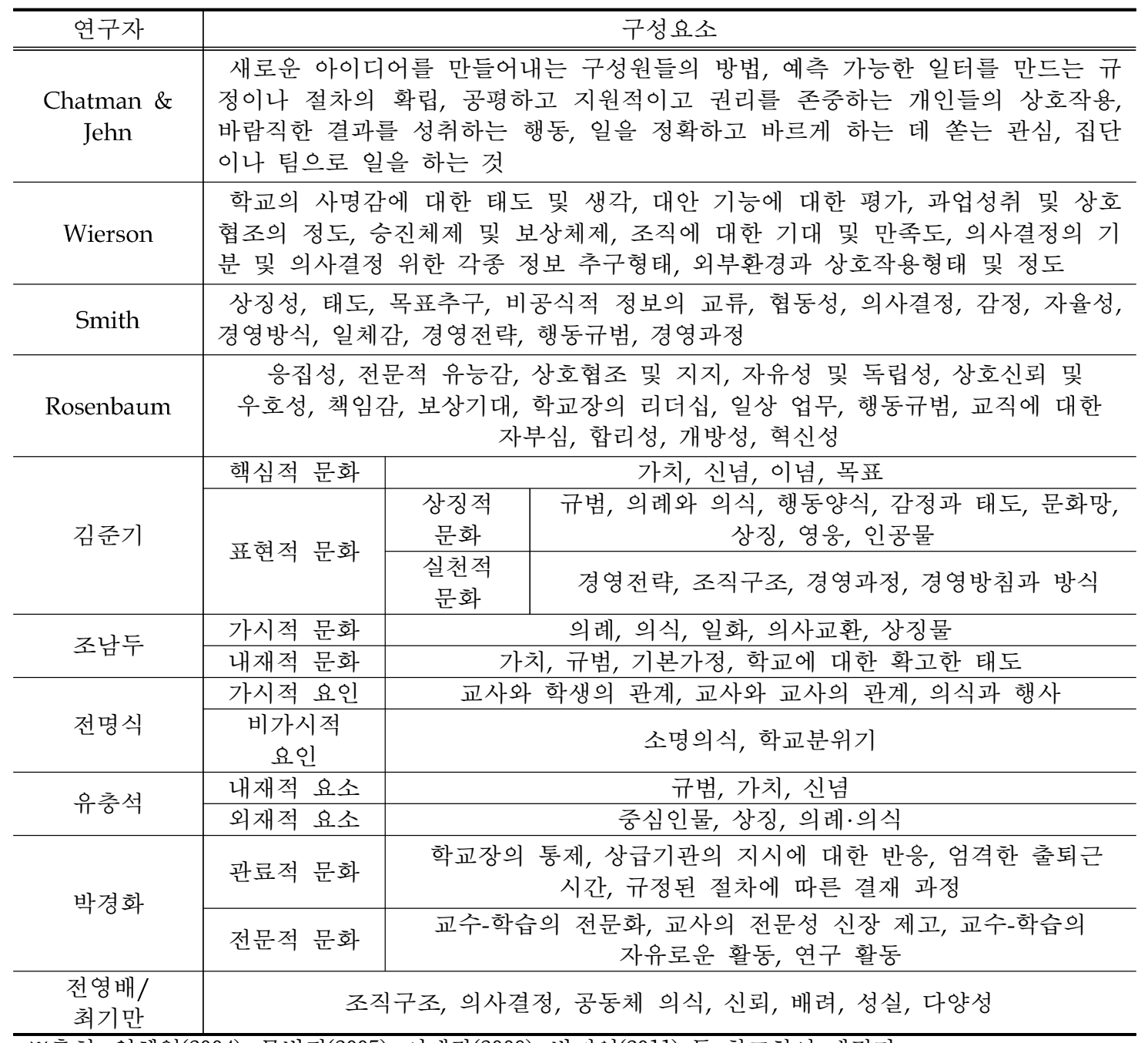

※출처: 임혜영(2004), 문병권(2005), 이애란(2009), 박지연(2011) 등 참고하여 재정리 


\section{3. 학교조직문화 측정요소의 설정}

학교조직문화에 대한 선행 연구는 주제별로 상 당히 다양하게 많이 연구되어 있다. 본 연구에서 는 학교조직문화의 측정요소에 대한 선행 연구들 을 중심으로 고찰해 보고자 한다. 학교조직문화 의 측정도구와 구성요소에는 몇 가지 공통점이 있다. 첫째, 조직문화를 조직구성원이 공유하는 기본적 가설, 가치, 규범으로 보고 있는 것이고,
둘째로는 학교조직문화를 측정하기 위해 서로 다 른 접근 방식을 취하고 있다는 것이며, 셋째는 타 조직의 조직문화를 측정하기 위한 것이 아니 라 학교조직의 문화를 측정하는데 초점을 맞추고 있다는 것이다(이기룡.김한분, 1998). 이러한 학교 조직문화를 측정하기 위한 도구로는 <표 3>에서 확인할 수 있다.

〈표 3〉 학교조직문화 측정도구

\begin{tabular}{|c|c|c|}
\hline 측정도구 & 기본전제 & 요소 \\
\hline $\begin{array}{l}\text { School Work } \\
\text { Culture(Snyder, 1998) }\end{array}$ & $\begin{array}{l}\text { 조직의 효과성 증진을 } \\
\text { 위해 교육프로그램과 } \\
\text { 구조에 대한 변경 시도 }\end{array}$ & $\begin{array}{l}\text { 학교계획, 전문적 발달, 프로그램 발달, } \\
\text { 학교평가 }\end{array}$ \\
\hline $\begin{array}{l}\text { School Culture Assesment } \\
\text { Questionnaire(Sashkin, } \\
\text { 1990) }\end{array}$ & $\begin{array}{l}\text { 조직의 생존을 위한 } \\
\text { 조직의 기능수행에 중점 }\end{array}$ & $\begin{array}{l}\text { 문화의 강도, 변화관리, 조직력 성취와 } \\
\text { 지역사회 지향 }\end{array}$ \\
\hline $\begin{array}{l}\text { School Culture Elements } \\
\text { Questionnaire(Cavanagh } \\
\text { \& Dellar, 1997) }\end{array}$ & $\begin{array}{l}\text { 교사들의 인간관계는 교실 } \\
\text { 수업에 영향을 미침 }\end{array}$ & $\begin{array}{l}\text { 교사 효과성, 학습에 대한 강조, } \\
\text { 인간관계, 협동, 계획의 공유, 변화지향적 } \\
\text { 지도성 }\end{array}$ \\
\hline $\begin{array}{l}\text { School Culture } \\
\text { Survey(Saphier \& King, } \\
\text { 1985/Edwards, Green \& } \\
\text { Lyons, 1996) }\end{array}$ & $\begin{array}{l}\text { 교사들이 가지고 있는 } \\
\text { 업무추진방식이 } \\
\text { 학교문화에 영향을 미침 }\end{array}$ & $\begin{array}{l}\text { 교사의 전문성과 목표설정, 교육을 위한 } \\
\text { 행정 }\end{array}$ \\
\hline $\begin{array}{l}\text { Professional Culture } \\
\text { Questionnaire for Primary } \\
\text { Schools(Staessens, 1990) }\end{array}$ & $\begin{array}{l}\text { 문화는 사회적 실체로써, } \\
\text { 조직 구성원에게 중요한 } \\
\text { 의미를 가진 것으로 } \\
\text { 이해됨 }\end{array}$ & $\begin{array}{l}\text { 교사의 협동, 문화의 창조자, 수행자로서 } \\
\text { 학교장, 목표에 대한 합의, 교사들 간의 } \\
\text { 인간관계 }\end{array}$ \\
\hline $\begin{array}{l}\text { School Values Inventory } \\
\text { form- I (Pang, 1996) }\end{array}$ & $\begin{array}{l}\text { 가치는 조직을 운영해 } \\
\text { 나가는 가시적-비가시적 } \\
\text { 요소의 혼합 }\end{array}$ & $\begin{array}{l}\text { 전문적 지원에 대한 부족, 공식성과 } \\
\text { 통제, 관료적 합리성, 성취지향, 참여와 } \\
\text { 협동, 인간관계 }\end{array}$ \\
\hline
\end{tabular}

※출처: 이기룡 - 김한분(1998)에서 인용

이 외에도 위와 유사한 측정도구로는 Sashkin (1997)이 개발한 OBQ(Organizational Beliefs Questionnaire : 조직신앙질문지)와 Halpin \& Croft(1963)의 OCDQ(Organizational Climate Description Questionnaire : 조직풍토기술질문지) 가 있다.

이상에서 살펴본 것과 같이 학교조직문화의 구 성요소와 측정도구의 요소들을 근거로 본 연구에
서는 학교조직문화 구성요소로 전영배(1993)가 실증적인 방법을 통해 선정한 요소들을 기본 틀 로 삼고, 박경화(2001), 강경희(2004) 등이 중요 변인요소로 언급하였고, 황용규(2001), 구순희 (2003) 등이 사용한 전문성 영역과 현재 학교조 직에서 가장 절실하다고 판단되는 의사결정, 공 동체 의식, 배려성을 하위영역으로 선정하였으며, 각 하위영역의 조작적 정의는 <표 $4>$ 와 같다. 
대부분의 연구들이 대체적으로 7 개의 변인을 이 연구의 틀로 사용하고 있었는데, 본 연구에서 는 시대적 변화와 이에 요구되는 교육적 과제들 을 감안, 현재 학교조직에서 가장 필요로 하고 또 절실하게 보완해야 할 요소라고 판단된 것들 을 중심으로 변인들을 선정하여 정의하였다.

〈표 4> 학교조직문화의 측정변인과 조작적 정의

\begin{tabular}{l|l}
\hline 측정 변인 & \multicolumn{1}{|c}{ 조작적 정의 } \\
\hline \hline \multirow{3}{*}{ 전문성 } & $\begin{array}{l}\text { 조직의 목표 설정과 달성의 능력 } \\
\text { 을 포함한 전문직의 조건적 자질 } \\
\text { 과 신장하려는 노력 }\end{array}$ \\
\hline \multirow{3}{*}{ 의사결정 } & $\begin{array}{l}\text { 조직의 문제해결 과정에서 구성 } \\
\text { 원에게 주어지는 책임과 기회의 } \\
\text { 정도와 약간의 자율성 }\end{array}$ \\
\hline 공동체 의식 & $\begin{array}{l}\text { 조직 구성원이 갖고 있는 조직에 } \\
\text { 간의 신뢰감괌 상대방에 대한 약 }\end{array}$ \\
\hline \multirow{3}{*}{ 배려성 } & $\begin{array}{l}\text { 조직 구성원이 능력 발휘 결과에 } \\
\text { 따른 적절한 격려와 성실하고 정 } \\
\text { 직하게 생활하는 약간의 성실성 }\end{array}$ \\
\hline
\end{tabular}

\section{III. 연구 방법}

\section{1. 연구 대상}

본 연구는 중등교사의 학교조직문화에 대한 인 식과 교사의 직무만족간의 관계 연구로써 부산광 역시 소재 중등학교 교사를 대상으로 설문조사 방식으로 실시하였으며, 연구대상의 설문지 분 석 결과와 배경 변인별 분석대상 표집 현황은 다 음 <표 5 >와 같다.

\section{2. 측정 도구}

학교조직문화에 대한 교사의 인식을 알아보기 위한 측정도구는 선행 연구의 설문지 구성방식을 토대로 수정.보완하여 4 개의 하위영역을 설정하 였고, 각 영역별 문항은 4 개로 구성하였으며, 응 답은 Likert식 5단계 척도(5-매우 긍정, 4-긍정, 3-
보통, 2-부정, 1-매우 부정)를 사용하였다. 설문지 의 문항 구성과 내용 및 신뢰도계수는 다음 <표 $6>$ 과 같다.

\section{〈표 5〉 배경 변인별 분석 대상 표집 현황}

\begin{tabular}{|c|c|c|c|}
\hline 배경변인 & 구분 & 사례수 & 백분율 $(\%)$ \\
\hline \multirow{2}{*}{ 성별 } & 여 & 211 & 58.4 \\
\hline & 남 & 150 & 41.6 \\
\hline \multirow{4}{*}{ 교직경력 } & 1 4년 & 40 & 11.1 \\
\hline & 5 10년 & 64 & 17.7 \\
\hline & 11 20년 & 87 & 24.1 \\
\hline & 21년 이상 & 170 & 47.1 \\
\hline \multirow{2}{*}{ 학교구분 } & 공립 & 186 & 51.5 \\
\hline & 사립 & 175 & 48.5 \\
\hline \multirow{2}{*}{ 학교급 } & 중학교 & 172 & 47.6 \\
\hline & 고등학교 & 189 & 52.4 \\
\hline \multirow{3}{*}{ 학교규모 } & $\begin{array}{c}12 \text { 학급 } \\
\text { 이하 }\end{array}$ & 20 & 5.5 \\
\hline & 13 35학급 & 320 & 88.6 \\
\hline & $\begin{array}{c}36 \text { 학급 } \\
\text { 이상 }\end{array}$ & 21 & 5.8 \\
\hline \multicolumn{2}{|c|}{ 총계 } & 361명 & $100 \%$ \\
\hline
\end{tabular}

〈표 6〉 설문지의 문항 구성 및 신뢰도계수

\begin{tabular}{|c|c|c|c|}
\hline $\begin{array}{l}\text { 하위 } \\
\text { 영역 }\end{array}$ & 내 용 & $\begin{array}{c}\text { 문항 } \\
\text { 수 }\end{array}$ & $\begin{array}{l}\text { 신뢰도 } \\
\text { 계수 }\end{array}$ \\
\hline 전문성 & $\begin{array}{l}\text { 전문성 제고, 학습지도와 } \\
\text { 학급경영, 교수.학습지도 } \\
\text { 방법, 선진기자재 활용 }\end{array}$ & 4 & .951 \\
\hline $\begin{array}{l}\text { 의사 } \\
\text { 결정 }\end{array}$ & $\begin{array}{l}\text { 교사간 의사소통, 관리자 } \\
\text { 간 의사소통, 의사결정 } \\
\text { 참여도, 의사결정 형태 }\end{array}$ & 4 & .874 \\
\hline $\begin{array}{c}\text { 공동체 } \\
\text { 의식 }\end{array}$ & $\begin{array}{l}\text { 공동체 의식, 업무 우선 } \\
\text { 순위, 주인 의식, 교육문 } \\
\text { 제의 해결 방식 }\end{array}$ & 4 & .923 \\
\hline 배려성 & $\begin{array}{l}\text { 개인 발전의 지원 여부, } \\
\text { 개인 욕구와 복리, 관리 } \\
\text { 자 태도, 교사의 적성과 } \\
\text { 희망 }\end{array}$ & 4 & .912 \\
\hline 전체 & & 16 & .917 \\
\hline
\end{tabular}




\section{3. 분석 방법}

본 연구에서 수집된 자료는 SPSSWIN(Ver. $19.0)$ 통계 프로그램을 활용하여 다음과 같이 분 석하였다.

첫째, 본 연구에서 사용된 검사도구의 신뢰도 를 추정하기 위해 Cronbach's $\alpha$ 계수를 산출하 였다.

둘째, 본 연구에서 제시한 연구문제를 규명하 기 위해 성별, 학교구분, 학교급 차이는 집단 간 $\mathrm{t}$ 검증을 하고, 교직경력, 학교규모 차이는 변량분 석(Analysis of Variance : ANOVA)과 집단 간 구체적인 차이를 알아보기 위해 Scheffe의 사후 검증을 실시하였다.

\section{IV. 연구 결과 및 논의}

\section{1. 교사의 개인 배경변인별 분석 결과}

중등학교 교사의 학교조직문화에 대한 인식의 하위요인별 기술통계값은 <표 7>과 같다. 본 연 구에서 설정한 학교조직문화의 하위변인인 전문 성, 의사결정, 공동체 의식, 배려성에 대해 평균 3.0 이상으로 대부분 긍정적으로 평가하고 있음 을 볼 수 있다. 다만, 학교 조직문화변인에서 상 대적으로 배려성이 평균이 하인 것은 학교사회
에서도 이미 개인주의 성향이 만연된 까닭으로 판단된다.

〈표 7> 학교조직문화 변인별 평균과 표준편차

\begin{tabular}{lccccc}
\hline 변인 & 하위 변인 & 최소값 최대값 & $\mathrm{M}$ & $\mathrm{SD}$ \\
\hline \hline 학 & 전문성 & 1 & 5 & 3.674 & 0.657 \\
\cline { 2 - 6 } 교 & 의사결정 & 1 & 5 & 3.395 & 0.871 \\
\cline { 2 - 6 } 족 직 & $\begin{array}{c}\text { 공동체 } \\
\text { 의식 }\end{array}$ & 1 & 5 & 3.491 & 0.740 \\
\cline { 2 - 6 } 화 & 배려성 & 1 & 5 & 3.296 & 0.807 \\
\hline
\end{tabular}

가. 성별에 따른 인식의 차이

학교 조직문화 인식의 차이를 성별로 분석한 결과 전문성, 공동체 의식, 배려성에서 통계적으 로 유의미한 차이가 있는 것으로 나타났으며, 의 사결정은 통계적으로 유의미한 차이가 없는 것 으로 <표 $8>$ 과 같이 나타났다. 특히 전문성, 공 동체 의식, 배려성에서 모두 여자가 남자보다 더 욱 긍정적으로 인식하는 것으로 나타났다. 이는 <표 5>의 성별에 따른 배경 변인별 분석 대상 표집 현황에서와 같이 설문 응답자 중에 중학교 는 여자 교사의 비율 $(72.1 \%)$ 이 남자 교사 $(27.9 \%)$ 에 비해 압도적으로 높았고, 고등학교는 여자 교 사 $(46.0 \%)$ 에 비해 남자 교사 비율 $(54.0 \%)$ 이 조금 높았는데, 남자 교사보다는 여자 교사가 학교조 직문화 인식에 민감한 것으로 사료된다.

〈표 8> 성별에 따른 학교 조직문화 인식의 차이

\begin{tabular}{|c|c|c|c|c|c|c|}
\hline 변인 & 하위 변인 & $\mathrm{N}$ & $\mathrm{M}$ & SD & $t$ & $\mathrm{p}$ \\
\hline \multirow{2}{*}{ 전문성 } & 여자 & 211 & 3.758 & 0.639 & \multirow{2}{*}{$2.927^{* *}$} & \multirow{2}{*}{.004} \\
\hline & 남자 & 150 & 3.555 & 0.665 & & \\
\hline \multirow{2}{*}{ 의사결정 } & 여자 & 211 & 3.425 & 0.898 & \multirow{2}{*}{.774} & \multirow{2}{*}{.439} \\
\hline & 남자 & 150 & 3.353 & 0.833 & & \\
\hline \multirow{2}{*}{$\begin{array}{c}\text { 공동체 } \\
\text { 의식 }\end{array}$} & 여자 & 211 & 3.605 & 0.712 & \multirow{2}{*}{$3.543^{* * *}$} & \multirow{2}{*}{.000} \\
\hline & 남자 & 150 & 3.330 & 0.749 & & \\
\hline \multirow{2}{*}{ 배려성 } & 여자 & 211 & 3.370 & 0.788 & \multirow{2}{*}{$2.076^{*}$} & \multirow{2}{*}{.039} \\
\hline & 남자 & 150 & 3.192 & 0.824 & & \\
\hline
\end{tabular}

${ }^{*} \mathrm{p}<.05,{ }^{* *} \mathrm{p}<.01,{ }^{* * *} \mathrm{p}<.001$ 
이러한 성별에 따른 학교조직문화의 차이들을 논의해 보면, 박임숙(2002)은 '공.사립 중등학교 학교조직문화 비교연구'에서 여자교사보다 남자 교사들이 더 높게 학교조직문화를 인식한다고 했고, 문병권(2005)도 '학교조직문화와 교사의 직 무만족의 관계'에서 여자교사보다도 남교사들이 학교조직문화에 대해 더 높게 결과가 나타났다 고 했으며, 이규배(2007)도 '학교조직문화와 직무 만족과의 관계 연구'에서 여교사보다 남교사가 학교조직문화 인식에 더 높게 인식한다고 했다.

이것으로 볼 때, 지금까지는 남교사가 학교조 직문화에 대해 더 높게, 긍정적으로 인식하고 있 었지만, 본 연구에서는 남자교사보다 여자교사가 학교조직문화에 더욱 긍정적으로 높게 인식하고
있다. 이러한 인식의 변화는 시대적 흐름과 전혀 무관하지 않을 것으로 사료된다. 조직문화에 대 한 일반적 견해로 남자가 더 조직문화에 익숙하 고 잘 알 것이라는 편견을 바꾸어 놓기에 충분 한 것으로 판단되며 여초현상으로 인해 학교조 직운영의 폐해가 심각할 것이라는 것도 잠식시 키기에 충분할 것으로 보인다.

\section{나. 교직경력에 따른 인식의 차이}

교직경력에 따른 학교 조직문화에 대한 인식 의 차이를 분석한 결과 의사결정 영역과 배려성 영역에서 집단 간 유의미한 차이가 있는 것으로 나타났으며, 전문성 영역과 공동체 의식 영역에 서는 집단 간 유의미한 차이가 없는 것으로 <표 9>와 같이 나타났다.

〈표 9> 교직경력에 따른 학교 조직문화 인식의 차이

\begin{tabular}{|c|c|c|c|c|c|c|c|}
\hline 변인 & 하위 변인 & $\mathrm{N}$ & M & SD & $\mathrm{F}$ & $\mathrm{p}$ & scheffe \\
\hline \multirow{4}{*}{ 전문성 } & 1 1 4년1) & 40 & 3.688 & 0.557 & \multirow{4}{*}{1.561} & \multirow{4}{*}{.199} & \multirow{4}{*}{ N.S } \\
\hline & 5 10년2) & 64 & 3.652 & 0.592 & & & \\
\hline & 11 20년 ${ }^{3)}$ & 87 & 3.555 & 0.731 & & & \\
\hline & 21년 이상-4) & 170 & 3.740 & 0.659 & & & \\
\hline \multirow{4}{*}{ 의사결정 } & 1 4년 ${ }^{1)}$ & 40 & 3.563 & 0.652 & \multirow{4}{*}{$4.992^{* *}$} & \multirow{4}{*}{.002} & \multirow{4}{*}{$4>3$} \\
\hline & 5 10년2) & 64 & 3.371 & 0.836 & & & \\
\hline & 11 20년 ${ }^{3)}$ & 87 & 3.103 & 0.940 & & & \\
\hline & 21년 이상-4) & 170 & 3.515 & 0.862 & & & \\
\hline \multirow{4}{*}{$\begin{array}{c}\text { 공동체 } \\
\text { 의식 }\end{array}$} & 1 4년 ${ }^{1)}$ & 40 & 3.600 & 0.686 & \multirow{4}{*}{1.670} & \multirow{4}{*}{.173} & \multirow{4}{*}{ N.S } \\
\hline & 5 10년2) & 64 & 3.527 & 0.683 & & & \\
\hline & 11 20년 ${ }^{3)}$ & 87 & 3.342 & 0.803 & & & \\
\hline & 21년 이상4) & 170 & 3.528 & 0.734 & & & \\
\hline \multirow{4}{*}{ 배려성 } & 1 4년 ${ }^{1)}$ & 40 & 3.388 & 0.599 & \multirow{4}{*}{$2.980^{*}$} & \multirow{4}{*}{.031} & \multirow{4}{*}{$4>3$} \\
\hline & 5 10년2) & 64 & 3.262 & 0.719 & & & \\
\hline & 11 20년(3) & 87 & 3.089 & 0.893 & & & \\
\hline & 21년 이상 ${ }^{4}$ & 170 & 3.393 & 0.819 & & & \\
\hline
\end{tabular}

${ }^{*} \mathrm{p}<.05,{ }^{* *} \mathrm{p}<.01,{ }^{* * *} \mathrm{p}<.001$

의사결정 영역에서는 교직경력 21년 이상 교 사가 11 20년 교사보다 더욱 긍정적으로 인식하 고 있으며 이는 교직경력 21년 이상의 교사들이 11 20년 교사들보다 학교조직 내에서 차지하는 위치가 좀 더 의사결정면에서 좀 더 자유롭고 영향력인 있는 것으로 인식하는 것으로 사료되
고. 배려성 영역에서도 교사경력 21년 이상 교사 가 11 20년 교사보다 더욱 긍정적으로 인식하고 있으며 이도 역시 교직경력 21년 이상의 교사들 이 11 20년 교사들보다 학교조직 내에서 자신들 이 타인을 좀 더 많이 배려하고 있다고 인식하 는 것으로 사료된다. 상대적으로 생각하면 교직 
경력 11 20년 교사들이 학교조직의 위치적인 면 으로 볼 때 21 년 이상 교사들에게 의사결정이 덜 자유롭고 그들을 더 많이 배려하는 것으로 인식하는 것으로 사료된다.

이러한 교직경력에 따른 학교조직문화의 차이 들을 논의해 보면, 문병권(2005)은 20년 이상 경 력이 많은 교사들이 더 높게 학교조직문화를 인 식한다고 했고, 이규배(2007)는 교직경력이 20년 이상의 교사들보다 11 20년인 교사들이 더 높게 학교조직문화를 인식한다고 했다. 하지만 본 연 구의 결과는 교직경력이 20 년 이상의 교사들이 학교조직문화를 더 긍정적으로 높게 인식하는 것은 같지만, 11 20년의 교사들이 가장 낮게 인 식하고 있는 것으로 나타났다. 이러한 결과는 학 교조직에서 볼 때, 11 20년 교사들이 많은 학교 에서 업무상 중추적인 역할을 맡고 있는 것으 로 업무량이 과다할 뿐만 아니라 20년 이상의 경력교사들의 업무회피 영향도 적지 않을 것으 로 보인다. 담임기피, 보직기피, 학년기피, 학생 기피와 같은 현상들의 결과가 연령이나 호봉 순
에서 밀리는 중간층인 11 20년 교사들의 몫일 것이다. 최근 일련의 제도적 변화들은 교사들은 되도록 학생들과 접촉(간섭)을 적게 하려고 하고 그래야 좋은 결과의 평가 점수를 받는 경향을 더욱 짙게 한다. 교육현장에서는 학생 생활지도 는 하지 않는 것이 좋은 점수를 받는 것이라는 인식이 팽배해 있으며, 사실상 학교에서는 생활 지도업무가 최고의 기피 업무임을 간접적으로 시사하고 있음을 의미한다고 볼 수 있다.

\section{2. 교사의 학교 배경변인별 분석 결과}

가. 학교구분에 따른 인식의 차이

학교조직문화 인식의 차이를 학교구분에 따라 분석한 결과 전문성, 의사결정, 공동체 의식, 배 려성 모든 항목에서 공립학교가 높게 나왔고 통 계적으로도 유의미한 차이가 있는 것으로 <표 $10>$ 과 같이 나타났다. 즉 전문성, 의사결정, 공 동체 의식, 배려성에서 모두 공립학교가 사립학 교보다 더욱 긍정적으로 인식하고 있었다.

〈표 10〉 학교구분에 따른 학교 조직문화 인식의 차이

\begin{tabular}{|c|c|c|c|c|c|c|}
\hline 변인 & 하위 변인 & $\mathrm{N}$ & $\mathrm{M}$ & SD & $\mathrm{t}$ & $\mathrm{p}$ \\
\hline \multirow{2}{*}{ 전문성 } & 공립 & 186 & 3.809 & 0.616 & \multirow{2}{*}{$4.123^{* * *}$} & \multirow{2}{*}{.000} \\
\hline & 사립 & 175 & 3.530 & 0.671 & & \\
\hline \multirow{2}{*}{ 의사결정 } & 공립 & 186 & 3.589 & 0.825 & \multirow{2}{*}{$4.460^{* * *}$} & \multirow{2}{*}{.000} \\
\hline & 사립 & 175 & 3.190 & 0.873 & & \\
\hline \multirow{2}{*}{$\begin{array}{c}\text { 공동체 } \\
\text { 의식 }\end{array}$} & 공립 & 186 & 3.620 & 0.691 & \multirow{2}{*}{$3.458^{* *}$} & \multirow{2}{*}{.001} \\
\hline & 사립 & 175 & 3.354 & 0.767 & & \\
\hline \multirow{2}{*}{ 배려성 } & 공립 & 186 & 3.512 & 0.745 & \multirow{2}{*}{$5.461^{* * *}$} & \multirow{2}{*}{.000} \\
\hline & 사립 & 175 & 3.066 & 0.808 & & \\
\hline
\end{tabular}

${ }^{* *} \mathrm{p}<.01,{ }^{* * *} \mathrm{p}<.001$

이것은 공·사립의 특성에서 기인하는 인식의 결과로 공립은 승진과 보상, 업무의 처리나 시행 등에 있어서 공립과는 다른 또 다른 비선조직이 나 계통의 영향을 많이 받는다. 사립은 전문성 신장 측면에서 공립보다는 소극적이다. 또한 의 사결정에서도 인화차원 내지는 비선조직, 사립학
교의 실세들의 영향력이 크고, 공동체 의식 차원 에서도 마찬가지로 그들의 영향력은 크게 작용 한다. 그리고 개인의 자기발전이나 계발을 위한 배려성 측면에서는 개인적인 희생을 감수해야 한다. 업무배정이나 처리에 있어서도 봉사정신이 매우 요구된다. 즉 주류가 아닌 비주류일 경우에 
는 근무하기가 매우 힘든 실정이고 관리자들과 도 그렇게 원활하지 못한 경우가 많기 때문으로 판단된다. 공립은 일정기간 근무 후에 다른 곳으 로 이동도 하고, 업무처리가 대체적으로 합리적 이고 객관적인 기준이나 규정에 따르는 경향이 강한 반면에, 사립은 임용에서부터 퇴임까지 한 곳에서 계속 근무해야 하기 때문에 업무처리에 있어서 그 어떤 기준이나 규정보다도 전체적인 인화차원, 또는 대인관계 측면이 더 우선적으로 생각하는 경향이 강하기 때문인 것으로 사료된 다.

이러한 학교구분에 따른 학교조직문화의 차이 들을 논의해 보면, 박임숙(2002)은 사립 중등교 사가 전반적으로 공립보다 더 높게 학교조직문 화를 인식한다고 했다. 이것은 사립교사들이 한 곳에 오래 머무르면서 학교에 대한 사랑과 이해 심, 가족과 같은 분위기 등이 긍정적으로 작용한
결과라고 했는데, 교육현장의 급격한 변화는 이 것을 뒤바꾸어 놓았다. 본 연구에서는 정반대의 결과가 나타났는데, 사립학교의 환경들이 냉엄한 평가와 현실의 변화 앞에 사립의 특성들이 역작 용의 결과를 가져오게 한 것으로 사료된다. 객관 적이고 합리적인 기준들이 소홀히 되고 사립학 교의 주관적 기준과 특성들이 변화된 교육현장 의 평가 잣대가 됨에 따라 인식의 변화가 초래 된 것으로 볼 수 있다.

나. 학교급에 따른 인식의 차이

학교조직문화 인식의 차이를 학교급에 따라 분석한 결과는 <표 $11>$ 과 같다. 하위영역 중 전 문성, 공동체 의식에서 통계적으로 유의미한 차 이가 있는 것으로 나타났으며, 의사결정, 배려성 은 통계적으로 유의미한 차이가 없는 것으로 나 타났다.

〈표 11〉 학교급에 따른 학교 조직문화 인식의 차이

\begin{tabular}{|c|c|c|c|c|c|c|}
\hline 변인 & 하위 변인 & $\mathrm{N}$ & $\mathrm{M}$ & $\mathrm{SD}$ & $t$ & $\mathrm{p}$ \\
\hline \multirow{2}{*}{ 전문성 } & 중학교 & 172 & 3.881 & 0.622 & \multirow{2}{*}{$5.980^{* * *}$} & \multirow{2}{*}{.000} \\
\hline & 고등학교 & 189 & 3.485 & 0.632 & & \\
\hline \multirow{2}{*}{ 의사결정 } & 중학교 & 172 & 3.391 & 0.923 & \multirow{2}{*}{-.092} & \multirow{2}{*}{.927} \\
\hline & 고등학교 & 189 & 3.399 & 0.823 & & \\
\hline \multirow{2}{*}{$\begin{array}{c}\text { 공동체 } \\
\text { 의식 }\end{array}$} & 중학교 & 172 & 3.583 & 0.751 & \multirow{2}{*}{$2.264^{*}$} & \multirow{2}{*}{.024} \\
\hline & 고등학교 & 189 & 3.407 & 0.721 & & \\
\hline \multirow{2}{*}{ 배려성 } & 중학교 & 172 & 3.379 & 0.781 & \multirow{2}{*}{1.886} & \multirow{2}{*}{.060} \\
\hline & 고등학교 & 189 & 3.220 & 0.824 & & \\
\hline
\end{tabular}

${ }^{*} \mathrm{p}<.05,{ }^{* * *} \mathrm{p}<.001$

특히 전문성, 공동체 의식에서 모두 중학교가 고등학교보다 더욱 긍정적으로 인식하는 것으로 나타났는데, 이는 고등학교가 중학교에 비해 좀 더 전문화된 교육과정의 특성상 교과의 내용면 에서는 심화된 학습내용에 대한 전문성이 필요 하나 인식은 중학교보다 많이 느끼지 못하는 것 으로 나타나 인식의 전환을 위한 노력이 필요한 것으로 판단된다. 또한 개별교과 내지는 업무중 심의 특성상 고등학교는 중학교보다 전체보다는
개별 또는 부서별 친밀성향이 높은 것은 단위학 교당 중학교와 고등학교는 전체 교직원의 규모 가 최소 2 3배의 차이가 나는데, 고등학교의 특 정 한 두 교과의 교사의 수가 중학교의 전체 교 사의 수보다 많은 상태이므로 고등학교 교사의 공동체 의식에 대한 긍정적 인식이 중학교에 비 해 떨어지는 것으로 사료된다.

이러한 학교급에 따른 학교조직문화의 차이들 을 논의해 보면, 박임숙(2002)의 연구에서는 공. 
사립 중학교와 공.사립 고등학교 간에 비교 연 구결과에서 중학교는 차이가 없었고, 고등학교는 차이가 있었다고 했다. 그러나 본 연구에서는 공.사립을 구분하지 않고 중학교와 고등학교 간 의 차이를 보면 중학교가 고등학교에 비해 교사 들의 학교조직문화 변인 중에서 전문성과 공동 체 의식을 더 높게 긍정적으로 나타났는데, 이것 은 학교규모와 교과내용의 심화 차이와도 연관 이 많은 것으로 사료된다. 실제로 학급 수나 교
직원 수가 중학교와 고등학교는 단위학교당 약 2 배 정도 이상의 차이가 있었다.

다. 학교규모에 따른 인식의 차이

학교규모에 따른 학교 조직문화에 대한 인식 의 차이를 분석한 결과 전문성 영역에서 집단 간 유의미한 차이가 있는 것으로 나타났으며, 그 외 의사결정 영역과 공동체 의식 영역, 배려성 영역에서는 집단 간 유의미한 차이가 없는 것으 로 <표 $12>$ 와 같이 나타났다.

〈표 12〉 학교규모에 따른 학교 조직문화 인식의 차이

\begin{tabular}{|c|c|c|c|c|c|c|c|}
\hline 변인 & 하위 변인 & $\mathrm{N}$ & $\mathrm{M}$ & $\mathrm{SD}$ & $\mathrm{F}$ & $p$ & scheffe \\
\hline \multirow{3}{*}{ 전문성 } & 12학급이하1) & 20 & 3.488 & 0.367 & \multirow{3}{*}{$9.582^{* * *}$} & \multirow{3}{*}{.000} & \multirow{3}{*}{$2>3$} \\
\hline & 13 35학급2) & 320 & 3.722 & 0.665 & & & \\
\hline & 36학급이상 3$)$ & 21 & 3.119 & 0.452 & & & \\
\hline \multirow{3}{*}{ 의사결정 } & 12학급이하1) & 20 & 3.113 & 0.604 & \multirow{3}{*}{1.130} & \multirow{3}{*}{.324} & \multirow{3}{*}{ N.S } \\
\hline & 13 35학급 2$)$ & 320 & 3.410 & 0.899 & & & \\
\hline & 36학급이상 ${ }^{3)}$ & 21 & 3.440 & 0.580 & & & \\
\hline \multirow{3}{*}{$\begin{array}{c}\text { 공동체 } \\
\text { 의식 }\end{array}$} & 12학급이하1) & 20 & 3.263 & 0.714 & \multirow{3}{*}{2.352} & \multirow{3}{*}{.097} & \multirow{3}{*}{ N.S } \\
\hline & 13 35학급2) & 320 & 3.521 & 0.748 & & & \\
\hline & 36학급이상 ${ }^{3)}$ & 21 & 3.250 & 0.548 & & & \\
\hline \multirow{3}{*}{ 배려성 } & 12학급이하1) & 20 & 3.025 & 0.743 & \multirow{3}{*}{2.199} & \multirow{3}{*}{.112} & \multirow{3}{*}{ N.S } \\
\hline & 13 35학급2) & 320 & 3.327 & 0.822 & & & \\
\hline & 36학급이상 ${ }^{3)}$ & 21 & 3.071 & 0.507 & & & \\
\hline
\end{tabular}

$* * * \mathrm{p}<.001$

전문성 영역에서는 학교규모가 13 35학급 학 교 교사가 36 학급 이상의 학교 교사보다 더욱 긍정적으로 인식하고 있으며 이는 학교 규모가 너무 크거나 작은 경우보다도 어느 정도의 규모 가 되는 학교가 전문성을 발휘하기에 적절하다 고 인식하는 것으로 사료된다. 이러한 학교규모 에 따른 학교조직문화의 차이는 학교급에 의한 차이와 연관이 많은 것으로 추론할 수 있는 바, 학교급에 따라 중학교가 고등학교에 비해 교사 들의 학교조직문화 하위영역 중에서 전문성과 공동체 의식을 더 높게 긍정적으로 나타났는데 이것은 학교규모와 교과내용의 심화 차이와도 연관이 많은 것으로 사료된다.

\section{V. 결론 및 제언}

시대의 흐름은 학교현장에서도 많은 변화를 가져왔으며, 교육현장의 급격한 변화는 교육의 질 향상 차원에서 새롭고 바람직한 방향으로 이 루어져야 할 필요가 있다. 본 연구는 교사들의 학교조직문화에 대한 인식이 어떠한가를 파악하 고, 교사의 배경변인에 따른 집단간 학교조직문 화에 대한 인식의 차이를 분석해봄으로써 학교 조직의 효율적인 운영 및 학교조직문화의 개선 방향에 도움을 줄 수 있는 기초 정보를 제공하 기 위해 수행되었으며, 연구결과의 분석을 통해 도출된 결론은 다음과 같다.

첫째, 성별에 따른 학교조직문화 인식 분석 
결과, 전문성, 공동체 의식, 배려성에서 남자보다 여자 교사가 더욱 긍정적이었고, 교사의 직무만 족에서 교직자체에서도 남자보다 여자 교사가 더욱 긍정적이었다. 이는 기존에 일반적으로 갖 고 있는 여자 교사들에 대한 인식의 전환이 필 요함을 의미한다고 할 수 있다. 다수의 교사들이 갖고 있는 여교사들에 편견이나 선입관에서 보 면 여교사들이 학교 조직차원에서 볼 때, 남자 교사들에 비해 좀 더 개인주의적이고 타인을 배 려를 하지 않으며 공동체 의식이 조금 부족한 것으로 인식하고 있는데 연구결과를 보면 이에 대한 인식의 전환이 필요함을 알 수 있다.

둘째, 교직경력에 따른 학교조직문화 인식 분 석 결과, 교직경력이 11 20년 된 교사보다는 21 년 이상의 교사들이 의사결정이나 배려성 차원 에서 더욱 긍정적으로 인식하고 있다. 이것은 21 년 이상의 교사들이 학교조직에서 가장 중추적 인 역할을 하는 11 20년 교사들에 비해 모든 인 식적인 차원에서 좀 더 자유롭다는 것인데 초임 교사에서 원로교사가 되는 과정에서 11 20년의 시기가 과중한 업무 부담을 느끼는 시기라는 것 을 의미한다. 실제 학교 현장에서 소수의 몇 명 에게 업무가 과중하게 편중되어 있음을 알 수 있는데 이는 업무추진이나 효율적인 면에서도 바람직하지 않고 골고루 균등하게 분담하여 시 행하는 것이 필요하다는 것을 의미한다.

셋째, 학교구분에 의한 학교조직문화의 인식 차이를 보면 전문성, 의사결정, 공동체 의식, 배 려성 모든 항목에서 공립학교가 사립학교에 비 해 더욱 긍정적으로 인식하고 있고, 이것은 시간 이 지날수록 사립학교의 환경적 조건들이 공립 에 비해 현격한 차이가 나고 있다는 것을 확인 해 주는 것이다. 따라서 학교행정에서 보다 합리 적이고 객관적인 기준들이 잘 지켜져야 할 것이 고, 사립에 대한 정부차원의 지원책들이 공교육 의 바람직한 질 개선을 위해서라도 공립에 준하 는 사립학교에 대한 대안이 뒤따라야 할 것이다.

넷째, 학교급에 의한 학교 조직문화의 인식
차이를 보면 전문성, 공동체 의식에서 중학교가 고등학교보다 더욱 긍정적으로 인식하고 있었고, 이는 중학교가 고등학교에 비해 구성원의 수가 작고 교과적인 면에서 상대적으로 전문성에 대 한 인식이 높다는 것을 의미한다. 이러한 결과는 중학교에 비해 현행 교육체제상 중요한 다수의 결정적인 것들이 고등학교에 편중되어 있다는 것을 의미하는데, 대학입시와 그에 따른 책무성 등이 이 시기에 집중되어 있으므로 교사 업무 차원에서 볼 때 다수의 고등학교 교사들에게는 학교조직이 전문직보다는 노동직으로, 낮은 차원 의 보람감으로, 각종 잡무에 대한 피로감으로 시 달리고 있는 것으로 고등학교 교사들의 학교조 직문화에 대한 인식 변화와 직무만족을 높일 수 있는, 구체적이고 실질적인 대책이나 지원방안이 필요함을 시사한다.

다섯째, 학교규모에 의한 학교 조직문화의 인 식 차이를 보면 전문성에서 학교규모가 13 35학 급 학교에서 더욱 긍정적으로 인식하고 있었고, 이는 학교 규모는 너무 크거나 작은 것이 아닌 적당한 규모가 적절해야 한다는 것을 의미한다. 따라서 초미니 또는 초대형 학교는 정책적으로 적절한 규모의 학교로 전환해 가야 할 필요가 있음을 시사한다. 이상의 결론을 통하여 몇 가지 제언을 하면 다음과 같다.

첫째, 학교조직에서 성별이나 경력에 따른 선 입견이나 편견에 의한 직무수행의 부당한 차별, 비합리적인 업무의 분장 및 배제는 마땅히 사라 져야 할 것이다. 따라서 연수나 재교육 등의 다 양한 방법을 통해 학교조직의 구성원들 자체 노 력은 물론 학교 경영자들의 경영 마인드의 변화 가 있어야 할 것이다.

둘째, 학교조직에서 공립과 사립에 대한 기존 의 관념들은 버리고 공교육의 질 개선을 위해서 는 재단 관계자들의 더 많은 관심과 노력과 정 부 교육기관의 공정하고 균등한 지원이나 노력 들이 뒷받침되어야 할 것이다. 따라서 공립과 사 립에 대한 공공연한 구분에 의한 차별들은 사라 
져야 할 것이며, 중학교와 고등학교에 대한 특성 에 따른 세밀한 업무파악과 이에 대한 면밀한 방안 연구와 제도적 뒷받침을 통하여 고등학교 교사들의 직무만족 및 교직관, 학교조직문화에 대한 긍정적인 방향으로의 인식의 전환이 이루 어질 수 있는 노력이 있어야 할 것이다.

\section{참고 문헌}

강경희(2004). 중학교 교사들의 교직문화에 대한 인식과 직무만족도와의 관계 연구, 부경대학교 교육대학원 석사학위논문.

구순희(2003). 초등학교 조직문화의 특성과 교사 의 직무만족도와의 관계 연구, 위덕대학교 교 육대학원 석사학위논문.

김경미(2004). 중등학교 교직문화 특성에 관한 연구, 창원대학교 대학원 박사학위논문.

문병권(2005). 학교조직문화와 교사 직무만족의 관계, 전남대학교 교육대학원 석사학위논문.

박경화(2001). 학교조직문화에 따른 중등교사의 직무만족에 관한 연구, 숭실대학교 교육대학원 석사학위논문.

박영숙·전제상(2003). 교직활성화를 위한 교직문 화 변화 전략 개발 연구, 한국교육개발원 연구 보고 RR 2003-9.

박임숙(2002). 공·사립 중등학교 학교조직문화 비 교 연구, 창원대학교 교육대학원 석사학위논 문.

박지연(2011). 특수학교 교상의 학교 조직문화 인식 및 직무만족도 특성, 대구대학교 대학원 석사학위논문.

원효헌.남인애(2003). 중학교 교사의 교직사회화 단계별 교직의식 및 직무만족도 분석, 수산해 양교육연구 15(2), 145 153.

원효헌.조명임(2008). 중학교 교사의 의사결정 참 여수준과 조직효과성과의 관계, 수산해양교육
연구 20(2), 286 296.

이규배(2007). 학교 조직 문화와 직무 만족과의 관계 연구, 공주교육대학교 교육대학원 석사학 위논문.

이기룡·김한분(1998) 초등학교 조직문화 진단에 관한 연구, 국민대학교 교육논총 18(1).

이애란(2009). 학교장의 변혁적 지도성과 학교조 직문화의 관계, 서강대학교 교육대학원 석사학 위논문.

임혜영(2004). 초등학교 조직문화와 교사의 조직 헌신도와의 관계, 건국대학교 교육대학원 석사 학위논문.

전영배(1993), 학교조직문화 교사의 직무만족과 의 관계연구, 충남대학교 교육대학원 석사학위 논문.

조남근(1996). 학교조직문화 관련변인의 이론적 탐색, 교육문제연구 제8집, 123 128.

황기수(1998). 학교조직문화와 조직효과성과의 관계, 서강대학교 교육대학원 석사학위논문.

황용규(2001), 초등학교 조직문화 교원의 직무만 족과의 관계분석, 인천교육대학교 교육대학원 석사학위논문.

Halpin,A.W., \& Croft,D.(1963). The organizational climate of schools.

Hoy, W. K. \& Miskel, C.G.(1996, 2001, 2005). Educational Administration: Theory, Research, and Practive, McGraw-Hill International Edition.

Sashkin, H.(1997). Organizational Beliefs Questionnaire: Administrator's Technical Manual, Amherst, Massachusetts, HRD Press.

Schein, Edgar (1992). Organizational Culture and Leadership: San Francisco, CA: JosseyBass, Publishers, 9.

- 논문접수일 : 2013년 01월 06일

- 심사완료일 : 1차 - 2013년 01월 20일

- 게재확정일 : 2013년 01월 23일 